\title{
Isolamento de Salmonella spp. e Escherichia coli de psittaciformes: relevância em saúde pública
}

\author{
Isolation of Salmonella spp. and Escherichia coli \\ from psittacine: public health importance
}

\author{
Elisângela de Souza Lopes ${ }^{1}$, William Cardoso Maciel ${ }^{\text {* }}$, Régis Siqueira de Castro Teixeira', \\ Átilla Holanda de Albuquerque ${ }^{1}$, Ruben Horn Vasconcelos' ${ }^{1}$, Débora Nishi Machado', \\ Windleyanne Gonçalves Amorim Bezerra', Isabel Cristina Lima Santos'
}

RESUMO: O tráfico de animais selvagens consiste numa atividade ilegal exercida em diversas partes do mundo, e o Brasil, em função de sua grande extensão territorial e vasta biodiversidade, é um país bastante atingido por essa prática. O grupo de animais em perigo que mais se destaca é o das aves e, entre elas, as da ordem Psittaciformes. Essas são as mais traficadas por serem consideradas inteligentes e possuidoras de grandes habilidades de comunicação. Por isso, são retiradas indiscriminadamente da natureza. No entanto, as condiçóes em que essas aves são capturadas e mantidas em cativeiro favorecem o aparecimento de diversas enfermidades, entre elas as causadas pelas enterobactérias. As bactérias que mais causam mortes e problemas em psitacídeos são as do gênero Salmonella e Escherichia coli, responsáveis pela salmonelose e pela colibacilose, respectivamente. Este trabalho apresenta uma revisão da literatura sobre essas enterobactérias em Psittaciformes, ressaltando o potencial zoonótico desses agentes.

PALAVRAS-CHAVE: tráfico; zoonose; saúde pública.

\begin{abstract}
The illegal wildlife trade is widespread among several countries, and Brazil is one of the most frequently involved due to its great territorial extension and large diversity of animal species. Birds are the main target, and among them the Psittaciformes order, which are removed indiscriminately from nature, is one of the most frequently traded due to their intelligence and great communicating skills. However, the conditions in which these birds are captured and maintained in captivity favor several diseases, among them the ones caused by some Enterobacteriaceae. In this family, the most frequently associated bacteria to illnesses and deaths in psittacine are Salmonella and Escherichia coli, which cause salmonellosis and colibacillosis, respectively. Therefore, this study presents a review of the literature concerning these enterobacteria in Psittaciformes, emphasizing the zoonotic potential of these bacteria.
\end{abstract}

KEYWORDS: illegal wildlife trade; zoonosis; public health. 


\section{INTRODUÇÃO}

A família Psittacidae é composta por papagaios, araras e periquitos (Ravazzi; Conzo, 2008). Os psitacídeos são aves de beleza exuberante, inteligentes e com grande habilidade de comunicação (MiYaki et al., 1997), e isso tem despertado grande interesse dos homens na manutenção dessas aves como animais de estimaçáo, aumentando o número de criadores comerciais cadastrados pelo Instituto Brasileiro do Meio Ambiente e dos Recursos Naturais Renováveis (IBAMA) para a comercializaçáo de aves legalizadas, saudáveis e domesticadas.

Apesar da possibilidade da criação dos psitacídeos de forma legalizada, o alto preço dessas aves nos criadores comerciais faz com que haja procura por meio do mercado ilegal (LARA, 2006). Isso representa ameaça à vida silvestre, pois é estimado que cerca de $90 \%$ dos animais traficados morrem antes de chegar ao destino final, por conta das inadequadas condiçôes de captura, manutenção e transporte (Ribeiro; SiLVA, 2007). Vítimas das ações antrópicas, os animais selvagens são comumente levados para centros de triagem de animais selvagens (CETAS) e zoológicos (SAIDENBERG et al., 2012a), no entanto, tais centros são superlotados em funçáo da insuficiência de recursos e infraestrutura para atender à demanda de animais. Com isso, alta taxa de mortalidade é observada, resultado de inapropriadas condiçôes de vida (VANSTREels et al., 2010).

Embora exista controle no manejo sanitário, o ambiente de cativeiro, podendo ser zoológicos, criadores comerciais ou centros de triagem do IBAMA, continua sendo um local favorável para a disseminação de micro-organismos com potencial zoonótico (Sedgwick et al., 1975; Montali; Migaki, 1980; Siemering, 1986; Fowler, 1993; VANSTREels et al., 2010). A disseminação de micro-organismos nas criações de Psittaciformes pode afetar negativamente náo somente a saúde de outras aves, como também a de seres humanos. Várias doenças são transmitidas por aves de cativeiro ou de estimaçáo para o homem por intermédio do contato direto ou indireto das aves doentes ou portadoras, sendo as bactérias os agentes causadores mais comuns dessas zoonoses (АкHTER et al., 2010). Tendo em vista que as enterobactérias são um grupo de micro-organismos comumente encontrados na microbiota entérica de animais e do homem, algumas estirpes apresentam potencial zoonótico (KRUSE et al., 2004). Portanto, foram abordados nesta revisão o isolamento e a relevância de Salmonella e Escherichia coli diarreiogênicas e extraintestinais procedentes de Psittaciformes, assim como se quis destacar o potencial zoonótico de ambas as bactérias.

\section{DESENVOLVIMENTO}

\section{Enterobactérias}

Espécies de bactérias pertencentes à família Enterobacteriaceae são consideradas parte da microbiota autóctone intestinal de muitos mamíferos, incluídos os seres humanos e algumas espécies de aves. As bactérias dessa família têm a capacidade de se propagar no ambiente desde que tenham condiçóes adequadas. Além disso, são também apontadas como importantes patógenos aviários (GERLACH, 1994), ao causar infecções intestinais e extraintestinais (RItchie et al., 1994).

Muitos psitacídeos provenientes do tráfico de animais selvagens, quando são recolhidos por órgãos de fiscalização competente, encontram-se em péssimas condiçôes; muitos já mortos, dopados e/ou maltratados (SANTiAgo et al., 2010). Dessa forma, psitacídeos capturados e mantidos de maneira inadequada apresentam diminuição da capacidade imunológica e, com isso, ficam suscetíveis à infecção por diversos agentes patogênicos (HALL; SAITO, 2008).

É muito comum os psitacídeos terem enterites bacterianas, pois o estresse nessas aves faz com que ocorra o desequilíbrio da homeostasia do microambiente gastrointestinal, com alteração da resposta imune e imunodepressão. No entanto, o conhecimento da microbiota intestinal de psitacídeos ainda é escasso (AlLegretti, 2009).

As alteraçóes da microbiota e a frequência de problemas gastrointestinais dessas aves aumentam a preocupaçáo com a saúde intestinal. Os micro-organismos dessa família que estão presentes na maioria dos relatos científicos envolvendo as aves são as bactérias do gênero Salmonella e Escherichia coli, entretanto, em menor número também é possível encontrar informaçóes científicas a respeito de outros micro-organismos, tais como Shigella spp., Edwardsilella tarda, Proteus spp., Hafnia alvei, Serratia spp., Enterobacter cloacae, Citrobacter freundii e Klebsiella pneumoniae (HIDAsi et al., 2013; Lopes et al., 2015).

\section{Salmonella}

As bactérias do gênero Salmonella destacam-se por ser uma zoonose de importância para a saúde pública (KoRSAK et al., 2004). O gênero Salmonella possui duas espécies: Salmonella bongori, isoladas comumente de animais de sangue frio; e Salmonella enterica, que contém mais de 2.579 sorotipos. Dentre estes, 1.531 pertencem à subespécie enterica (Grimont; Weill, 2007), nos quais estão incluídos os sorotipos $S$. Pullorum e $S$. Gallinarum, causadores da pulorose e do tifo aviário, nessa ordem, que são específicos de aves (GAST, 2008) e cuja ocorrência vem sendo relatada na literatura científica sobretudo em aves domésticas e de maneira mais característica em Galliformes.

Salmonella sorotipo Pullorum é um patógeno comum de aves domésticas, mas tem baixa patogenicidade em outras espécies aviárias (Dhoust; Prescott, 2007), não sendo, provavelmente, causa importante de doença nem de mortalidade em aves livres na natureza (Friend; Frason, 1999). O mesmo ocorre em relação à Salmonella Gallinarum, que causa infecção primariamente em frangos e perus de todas as idades, mas 
a doença já foi descrita em patos, codornas, pombos, faisóes, pavôes e canários (BERCHIERI JR. et al., 2001). Recentemente, um surto de $S$. Gallinarum foi descrito em periquitos australianos (Melopsittacus undulatus), demonstrando que essas aves são bastante susceptíveis à infecção por esse sorotipo em comparação com outras aves (TunCA et al., 2012).

Todos os outros agentes desse sorotipo entérico são causadores da enfermidade conhecida como paratifo aviário, e a Salmonella enterica sorovar Enteritidis e Salmonella enterica sorovar Typhimurium (ST) se sobressaem nesse subgrupo por serem importantes causadoras de problemas relacionados a infecçóes alimentares no homem (BERCHIERI JúNIOR, 1999; GAMA et al., 2003), sobretudo no que se refere a produtos oriundos da indústria avícola, pois os ovos e a carne são as principais vias de transmissão da doença (BAÚ et al., 2001; КоттwITZ et al., 2008).

Apesar da problemática ligada às salmonelas paratíficas estar amplamente relacionada às aves domésticas e a seus subprodutos destinados ao consumo humano, a literatura científica também menciona a sua importância no que diz respeito à ocorrência desses patógenos em aves de vida livre. ST é o sorotipo mais isolado em ave de estimação e de vida livre (Dorrestein, 1997; Reavill, 1996). Esse sorotipo é relatado por ser frequentemente isolado em psitacídeos e, de acordo com VIGo et al. (2009), a ST pode se manifestar como um patógeno primário ou causar infecçôes subclínicas em aves jovens ou debilitadas. Ainda, o sorotipo ST tem sido descrito como um problema associado a casos de zoonoses envolvendo aves silvestres e, mais especificamente, psitacídeos. Thornley et al. (2003) investigaram 119 pacientes humanos na Nova Zelândia com diagnóstico de salmonelose e verificaram que $10,9 \%$ dos indivíduos que apresentavam o sorotipo ST tiveram contato com aves silvestres mortas. Madewell; McChesney (1975) relataram um caso de salmonelose com o isolamento do agente em criança, gato e dois periquitos que residiam no mesmo local.

Entre os sorotipos mais importantes associados à problemática de saúde pública, destaca-se Salmonella Enteritidis, que também já foi isolado de psitacídeos. Marietto-GonçALVES et al. (2010) isolaram esse patógeno em Amazona aestiva, espécie de psitacídeo comumente traficada e encontrada em diversas residências.

$\mathrm{O}$ isolamento desses sorotipos em aves de estimação ou provenientes do tráfico demonstra a importância sanitária que esses animais apresentam para o meio ambiente e para o homem (Marietto-Gonçalves et al., 2010; Lopes et al., 2015), pois o contato dessas aves com pessoas e outros animais, associado ao fato desses sorotipos náo terem hospedeiro determinado, pode induzir a elevados níveis de contaminação ambiental por essas bactérias (DAoust; Prescott, 2007).

Outros sorotipos de Salmonella também foram isolados de psitacídeos. Na Tabela 1 estão descritos os registros de ocorrência desse patógeno em diversas espécies de psitacídeos de cativeiro, de vida livre e do tráfico.
Algumas pesquisas científicas demonstraram casos de negatividade ou baixa frequência de isolamento de Salmonella spp. em psitacídeos. Um estudo realizado por SAREYYÜPOĞLU et al. (2008) analisou sete criatórios de periquitos australianos, canários e outras espécies de aves, totalizando 185 amostras. Os autores observaram a presença de Salmonella spp. apenas nas espécies Serinus canaria, Fringilla montifringilla e Taeniopygia guttata. Nenhuma das 27 amostras de fezes de psitacídeos (periquitos australianos) foi positiva. BEzERra et al. (2013) analisaram o total de 264 amostras de suabe de arrasto e suabe cloacais de periquitos australianos provenientes de pet shops e criadouros e, de acordo com a metodologia empregada, constataram ausência de Salmonella spp. A justificativa dada para a ausência do patógeno também se relacionava com a possível utilização de antibióticos, entretanto, outras medidas sanitárias aplicadas pelos criadores foram consideradas, tais como limpeza frequente do ambiente, bebedouro e comedouro, assim como a troca de água e ração.

O trabalho de Keen et al. (2007), por sua vez, permite averiguar a importância da ambiência e do manejo sanitário aos quais os animais estáo submetidos sobre a prevalência de Salmonella spp. Em uma análise em animais de zoológicos nos Estados Unidos envolvendo mamíferos e aves, observou-se 0,6\% de positividade entre 997 amostras de fezes avaliadas, e para todas as aves analisadas $(n=22)$, entre elas três papagaios, constatou-se negatividade. De acordo com os autores, a baixa prevalência desses micro-organismos em tais animais pode ser resultado de excelentes condiçôes nas instalações e de manejo.

Apesar das medidas sanitárias serem, indiscutivelmente, grande responsável pela baixa prevalência de Salmonella em aves e outros animais criados em cativeiro, Lopes et al. (2014) apresentaram outro argumento que pode justificar a baixa frequência de identificação de Salmonella spp. em amostras fecais. Refere-se à possibilidade da excreçáo intermitente desse micro-organismo pelas aves em condiçóes específicas, o que pode prejudicar a identificação do patógeno por intermédio das provas microbiológicas tradicionais, isso porque a bactéria talvez não esteja sendo eliminada durante o procedimento de coleta do material fecal. Esses pesquisadores investigaram 182 psitaciformes clinicamente sadios mantidos em criatórios comerciais e conservacionistas da Regiāo Metropolitana de Fortaleza e perceberam que apenas 1,65\% das aves eram positivas para Salmonella spp. Nesse caso, os pesquisadores concluíram que a baixa frequência para esse patógeno não implica necessariamente que um maior percentual dessas aves esteja livre do patógeno.

\section{Escherichia coli}

Escherichia colié uma bactéria anaeróbia facultativa Gram-negativa pertencente à microbiota intestinal dos animais, incluindo o homem, e estáo localizadas notadamente no ceco e colón (Tenaillon et al., 2010). Por ser encontrada abundantemente 
na microbiota de diversos animais, existe grande interaçáo dessa bactéria com o hospedeiro (Croxen; FinlaY, 2010). Estudos ainda são realizados para maior compreensáo acerca do papel comensal dessa bactéria na microbiota, mas se sabe que ela auxilia no processo de absorção de vitaminas e ao ocupar locais na mucosa intestinal, impedindo a fixação de bactérias patogênicas (Ferreira; KNöBl, 2009). Apesar da relação de mutualismo com o hospedeiro, essas bactérias possuem estirpes com características distintas de virulência, classificadas em patotipos diarreiogênicos e extraintestinais (Croxen; Finlay, 2010). Dessa maneira, as estirpes patogênicas podem apresentar-se nocivas à saúde humana ou animal.

Estirpes patogênicas de $E$. coli são responsáveis por inúmeras enfermidades em aves comerciais, podendo causar morte, diminuição na produção de ovos e condenação de carcaças nos abatedouros. A forma grave da doença é denominada de colisepticemia e caracteriza-se pela presença da bactéria no sangue, colonizando assim diversos órgãos, como o coração, fígado e pulmão (BARnes et al., 2008). A infecção por E. coli nas aves é considerada secundária a outros agentes patogênicos, e a manifestação da doença é predominantemente extraintestinal. A infecção inicia-se no trato respiratório, mais comumente nos sacos aéreos, após infecção primária, como, por exemplo, as ocasionadas por micoplasma. Infecçáo por E. coli nas aves pode resultar em pericardite, peri-hepatite e aerossaculite (McPeake $e t$ al., 2005). A veiculaçáo desse micro-organismo pode acontecer por meio de partículas de poeira, as quais contêm de $10^{5}$ a $10^{6} \mathrm{UFC}$ de E. coli por grama. As aves podem se infectar mediante a inalação de partículas contaminadas, facilitando a realização do isolamento dessa bactéria no trato respiratório superior. As secreçôes das aves infectadas podem facilitar a disseminação da bactéria, ocorrendo por intermédio do contato com as outras aves ou da ingestão de água ou ração contaminada (DHo-Moulin; FAIrbRother, 1999).

As aves silvestres podem ser tidas como importantes reservatórios naturais da bactéria. Estudos têm mostrado que a bactéria é facilmente isolada de várias espécies de passeriformes e especialmente de aves aquáticas de vida livre, principalmente em patos (Fallacara et al., 2001), no entanto, ainda estão sendo realizados diversos trabalhos em psitacídeos para melhor entender o papel da E. coli na microbiota. A maioria dos trabalhos envolve psitacídeos criados em cativeiro, mas sabe-se que estes possuem microbiota composta por bactérias Gram-positivas, coexistindo normalmente de forma protocooperativa. Todavia, estudo

Tabela 1. Ocorrência de sorotipos de Salmonella isolados de psitacídeos de cativeiro, de vida livre e vítimas do tráfico.

\begin{tabular}{|c|c|c|c|}
\hline Referência & $\begin{array}{l}\text { Local de isolamento } \\
\text { (país, ano) }\end{array}$ & Espécies da ave & Sorotipos \\
\hline PHILLIPS; HATKIN & Mississipi 1978 & Nymphicus hollandicus & Salmonella houtenae \\
\hline JONES; NISBET & Londres 1980 & Ara, Psittacus, Amazona, Cacatua sp. & Salmonella spp. \\
\hline Orosz et al. & Estados Unidos 1992 & Amazona finschi Schlatter, Pyrrhura molinae & Salmonella Enteritidis fagotipo 4 \\
\hline ORós et al. & Espanha, 1998 & Cacatua galerita & Salmonella arizonae \\
\hline MENÃo et al. & Brasil, 2000 & Anodorhynchus hyacinthinus & Salmonella Typhimurium \\
\hline GoPEE et al. & Trinidad, 2000 & Pionus menstruus & Salmonella do grupo $\mathrm{C}$ \\
\hline VILELA et al. & Brasil, 2001 & Anodorhynchus hyacinthinus & Salmonella Bredney \\
\hline KANASHIRO et al. & Brasil, 2002 & Agapornis roseicollis & $\begin{array}{l}\text { S. enterica subsp. enterica } \\
\text { sorovar } 5,4,12: \mathrm{i}\end{array}$ \\
\hline SEEPERSADSINGH; AdESIYUN & Trinidad, 2003 & Amazona spp. & Salmonella Newport \\
\hline WARD et al. & Indianápolis, 2003 & Trichoglossus, Lorius, Eos spp. & Salmonella Typhimurium \\
\hline JANG et al. & Coreia, 2008 & Ara ararauna & Salmonella Rissen \\
\hline ALLGAYER et al. & Brasil, 2009 & Anodorhynchus hyacinthinus & Salmonella Braenderup \\
\hline Vigo et al. & Argentina, 2009 & Ara ararauna & Salmonella Typhimurium \\
\hline OLIVEIRA et al. & Brasil, 2009 & Amazona aestiva e Amazona amazonica & Salmonella Hadar \\
\hline MARIETTO-GONÇALVES et al. & Brasil, 2010 & Amazona aestiva & Salmonella Enteritidis \\
\hline PICCIRILLo et al. & Itália, 2010 & Cacatua moluccensis & Salmonella Typhimurium DT 160 \\
\hline Tunca et al. & Turquia, 2012 & Melopsittacus undulatus & Salmonella Gallinarum \\
\hline HIDASI et al. & Brasil, 2013 & Não especificadas & Salmonella serovar Typhimurium \\
\hline LOPES et al. & Brasil, 2014 & Melopsittacus undulatus & Salmonella Newport \\
\hline LoPES et al. & Brasil, 2014 & Ara chloropterus & Salmonella Saintpaul \\
\hline LoPEs et al. & Brasil, 2014 & Amazona aestiva & Salmonella Lexington \\
\hline
\end{tabular}


realizado por SAIDenberg et al. (2015) em araras-azuis e araras-vermelhas de vida livre constatou que apenas $1,8 \%$ de 101 amostras de fezes analisadas eram positivas para micro-organismos Gram-negativos, e de acordo com os autores as bactérias podem ser apenas temporárias na microbiota dos psitacídeos saudáveis.

Em psitacídeos, a colonização intestinal por $E$. coli é dependente não somente do estado sanitário do animal, porém, também do ambiente em que se encontram, pois bactérias oriundas de outras aves que vivem em mesmo recinto e utilizam coletivamente os mesmos comedouros e bebedouros podem estar facilmente disseminando essas bactérias (MATtes et al., 2005). Essas aves, por conseguinte, quando encontradas em cativeiro, ficam mais vulneráveis à carga microbiana intestinal constituída comumente de bactérias Gram-negativas, mesmos os psitacídeos aparentemente saudáveis (JoNES; NISBET, 1980; Bowman; JaCobSon, 1980; BANGerT et al., 1988; FlaMmer; Drewes, 1988; Orosz et al., 1992; Marietto-GonçalVes et al., 2007; MATtes et al., 2005).

Xenoulis et al. (2010) compararam a microbiota entérica de psitacídeos selvagens e mantidos em cativeiro pela caracterização molecular, e os resultados mostraram que E. coli foi significativamente superior na microbiota de psitacídeos cativos, enquanto, em animais de vida livre, se observou predomínio de Pantoea sp. Os autores sugeriram, portanto, que essa diferença se deu em decorrência da manutenção em cativeiro, por causa de fatores como o ambiente, a dieta e o uso de antibióticos.

O problema envolvendo E. coli está associado sobretudo às cepas patogênicas. Estudos relacionados à patogenicidade de E. coli demonstraram que amostras patogênicas possuem mecanismos de virulência específicos. Nesse contexto, as cepas patogênicas de $E$. coli, causadoras de distúrbios em homens e animais, são divididas em dois grupos, as diarreiogênicas (DEC) e as extraintestinais (EXPEC). O primeiro grupo são as bactérias que provocam problemas de ordem intestinal classificadas em: enteropatogênica (EPEC), enterotoxigênica (ETEC), enteroinvasiva (EIEC), enterro-hemorrágica (EHEC), enteroagregativa (EaggEC) e enteropatogênica para coelhos (REDEC) (Ferreira; Knöbl, 2009). O grupo das extraintestinais (ExPEC) são: E. coli uropatogênica (UPEC), $E$. coli de meningite neonatal (NMEC) e $E$. coli patogênica para aves (APEC), responsáveis por uma variedade de infecçôes, incluindo as complicações no trato urinário, meningite e septicemia, respectivamente (KAPER et al., 2004).

E. coli diarreiogênicas como EPEC e EHEC representam os primeiros patotipos de E. coli descritos que causam diarreias. ETEC, EIEC e EaggEC ainda precisam de mais elucidação, mas sabe-se que cada grupo está associado a linhas genéticas identificáveis e a uma epidemiologia característica, assim como por promover reaçóes distintas no organismo. Cepas de EaggEC estáo ligadas a diarreia em crianças com menos de seis meses de idade que pode durar por semanas, ocasionando severa desnutrição (KeUsch; Acheson, 2009).

E. coli extraintestinais ExPEC têm a capacidade de colonizar diversas regiôes do organismo e disseminar-se pelo sangue, sistema nervoso central, trato urinário e vias respiratórias. Entre as ExPECs, há um subgrupo denominado de APEC normalmente isolado de aves de produçâo e patogênico apenas para esse grupo de animais (BARNEs, 2008; Barcelos, 2005). Em psitacídeos, mais estudos são necessários para melhor compreender a atuação das APECs no desencadeamento de enfermidades, entretanto, as pesquisas de Prioste et al. (2013) demonstraram que os psitacídeos podem ser reservatórios de estirpes patogênicas de E. coli. Os pesquisadores analisaram 87 estirpes isoladas de amostras fecais de ararajubas (Guaruba guarouba) clinicamente saudáveis, procedentes de seis zoológicos, três criatórios comerciais e um criatório conservacionista, e detectaram E. coli patogênica APEC em duas amostras, provenientes de um zoológico e um criador.

CORRÊA et al. (2013) averiguaram amostras de suabes cloacais $(n=15)$ e de inglúvio $(n=14)$ de psitacídeos considerados saudáveis e confirmaram 14 casos positivos de E. coli. A análise molecular revelou que para isolados dos suabes cloacais e de inglúvio o percentual de positividade para genes iss (resistência sérica) e iutA (sistema de aquisição de ferro) foi de 87,5 e $62,5 \%$, respectivamente. Também foi encontrada em 100 e $80 \%$ das amostras a detecção dos genes iss e iut $A$, nessa ordem. Diante desses resultados, os autores enfatizaram a importância da monitoria de $E$. coli e outras enterobactérias em criadores de aves silvestres, sobretudo psitacídeos, por conta do risco de disseminação dessa bactéria nos recintos, que ocorre em função da presença de aves portadoras assintomáticas, pois, além de contaminarem o ambiente, podem manifestar sinais clínicos na presença de fatores estressantes.

No tocante às EPEC de importância para a saúde humana, os psitacídeos também podem atuar como reservatórios desses agentes zoonóticos. SAIDENBERG et al. (2012a) relataram um caso de isolamento de EPEC oriundo de psitacídeos assintomáticos mantidos em cativeiro. Isso demonstra que o isolamento de cepas patogênicas de $E$. coli em psitacídeos pode representar um relevante problema de saúde pública, pois existe a possibilidade de transmissáo de $E$. coli dessas aves para o homem (Flammer, 1999).

Adicionalmente, Marietto-GonÇALVes et al. (2011) constataram a presença de cepas de E. coli EPEC, EAEC e STEC em pelo menos um isolado de psitacídeo, demostrando mais uma vez que essas aves podem ser reservatórios de cepas com potencial zoonótico. Outros patotipos de E. coli vêm sendo paulatinamente isolados em psitacídeos, como exemplificados por estudo realizado por KNöBl et al. (2011). Os pesquisadores, ao analisarem a presença dos sorogrupos $\mathrm{O} 7, \mathrm{O} 15, \mathrm{O} 21$, O23, O54, O64, O76, O84, O88, O128, O152 e O166 de 
genes de virulência de E. coli em 24 psitacídeos, puderam constatar a presença de EPEC e UPEC. Ou seja, as amostras apresentaram os mesmos fatores de virulência para esses patotipos. Genes de EPEC (eae) e STEC (stx2) foram isolados na pesquisa realizada por GioiA-Di CHIACCHIo et al. (2016) em calopsitas e periquitos australianos, psitacídeos comumente criados como animais de estimação.

A Tabela 2 traz um levantamento das pesquisas existentes na literatura científica que relatam a ocorrência de Escherichia coli diarreiogênicas e extraintestinais encontradas em psitacídeos de cativeiro e vida livre, destacando os genes isolados associados aos respectivos patotipos.

\section{Métodos de diagnóstico e tratamento}

O isolamento de bactérias Gram-negativas pode ser feito por intermédio de culturas microbiológicas de exsudatos, lesôes, cloaca ou cavidade oral, achados clínicos e patológicos e fragmentos de órgãos lesionados (Godoy, 2007).

O desenvolvimento de técnicas de identificação de micro-organismos deve levar em consideração sua sensibilidade e especificidade. A detecção de um agente etiológico pode ser dificultada pela quantidade de amostra, pela interaçáo com a microbiota competidora, por componentes inibidores nos alimentos e pela semelhança antigênica do micro-organismo com outras bactérias (BURTSCHER et al., 1999). A microbiologia convencional ainda é muito usada por ter custo mais acessível, porém, é um método demorado e demanda grande quantidade de meios para a identificação do agente (STONE et al., 1994). Entre os testes de custo mais acessível, o enzyme-linked immunosorbent assay (ELISA) tem sido uma ferramenta útil para monitorar infecção por Salmonella spp. em aves, uma vez que, embora a excreçáo não seja constante, a resposta sorológica persiste por vários meses (Barrow; Lovell, 1991). Porém, o uso de técnicas moleculares como a reação em cadeia da polimerase (PCR) é o modo mais rápido e sensível para detectar fatores de virulência bacteriana (KNöBL et al., 2008).

Antibióticos que agem em bactérias Gram-negativas são os indicados no tratamento inicial das infecçōes de aves até que se disponha do antibiograma, no entanto, utiliza-se para o tratamento de infecçóes causadas por bactérias Gram-negativas antibióticos de amplo espectro de ação, seguido do uso de complexos vitamínicos, de dieta balanceada e de manejo sanitário adequado (Godoy, 2007). Em casos de salmonelose e colibacilose, usam-se drogas com boa penetraçáo tecidual e celular, como a enrofloxacina e o cloranfenicol (RupLey, 1999), entretanto, KaNASHIRO et al. (2002) observaram que o uso

Tabela 2. Ocorrência de genes de Escherichia coli diarreiogênicas e extraintestinais em Psittaciformes de cativeiro e vida livre.

\begin{tabular}{|c|c|c|c|}
\hline Referência & Patotipo & Genes & Espécies da ave \\
\hline SCHREMMER et al. (1999) & DEC & eae, ebfpA & $\begin{array}{l}\text { Aprosmictus erythropterus } \\
\text { Cacatua moluccensis }\end{array}$ \\
\hline KNÖBL et al. (2008) & EXPEC & Crl, pap, iss, iuc, tsh & Papagaios (não especificados) \\
\hline \multirow[b]{2}{*}{ KNÖBL et al. (2011) } & DEC & eae & Amazona aestiva \\
\hline & EXPEC & pap, crl, csgA, iuc, iss e $t s h$ & $\begin{array}{c}\text { Amazona amazonica } \\
\text { Amazona aestiva } \\
\text { Aratinga aurea } \\
\text { Ara ararauna } \\
\text { Ara chloropterus }\end{array}$ \\
\hline \multirow[t]{2}{*}{ MARIETTO-GonÇALVES et al. (2011) } & DEC & eae, bfpA e stx & $\begin{array}{l}\text { Aratinga leucophthalmus } \\
\text { Amazona aestiva }\end{array}$ \\
\hline & EXPEC & Irp2 & Amazona aestiva \\
\hline SAIDENBERG et al. (2012a) & DEC & eae e $b f p$ & $\begin{array}{c}\text { Amazona amazonica } \\
\text { Amazona brasiliensis } \\
\text { Ara ararauna }\end{array}$ \\
\hline \multirow[b]{2}{*}{ SAIDENBERG et al. (2012b) } & DEC & eae & Anodorhynchus leari \\
\hline & EXPEC & sfa, iss, iuc, tsh e cnf 1 & $\begin{array}{c}\text { Amazona aestiva } \\
\text { Anodorhynchus hyacinthinus }\end{array}$ \\
\hline PRIOSTE et al. (2013) & EXPEC & iucD, iss, tsh, cvi/cva, irp2, astA e vat & Guaruba guarouba \\
\hline CORRÊA et al. (2013) & EXPEC & Iss e iutA & $\begin{array}{c}\text { Amazona pretrei, Ara ararauna, } \\
\text { Pionus maximiliani }\end{array}$ \\
\hline GIOIA-DI CHIACCHIO et al. (2016) & DEC & eae e stx2 & $\begin{array}{l}\text { Nymphicus hollandicus } \\
\text { Melopsittacus undulatus }\end{array}$ \\
\hline
\end{tabular}

DEC: Escherichia coli diarreiogênicas; EXPEC: Escherichia coli extraintestinais. 
da enrofloxacina náo demonstrou eficácia no tratamento de psitacídeos com salmonelose. Já a tetraciclina se mostrou eficaz para o tratamento de salmonelose e colibacilose em psitacídeos (MARIETTO-GonÇALVEs et al., 2010).

\section{CONSIDERAÇÕES FINAIS}

A tendência para os próximos anos é que aumente cada vez mais o interesse pela criação de psitacídeos em residências e criatórios em diversas partes do mundo, possibilitando contato mais íntimo do homem com essas aves. Dadas as diversas pesquisas que apontam a presença de bactérias zoonóticas como as do gênero Salmonella spp. cada vez mais frequente em psitacídeos, a preocupação com questóes de ordem sanitária deverá ter mais destaque nas pesquisas relacionadas a tais aves. Por conta da importância sanitária de enterobactérias patogênicas, sugerem-se mais esforços de prevenção e controle para evitar a presença desses patógenos no ambiente em que os psitacídeos estão alojados.

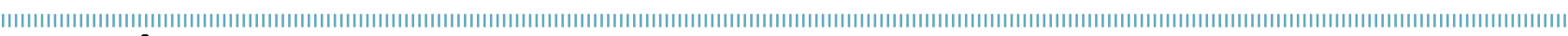
REFERÊNCIAS

AKHTER, J.; HOSSAIN, M.T.; ISLAM, M.T.; SIDDIQUE, M.P.; ISLAM, M.A. Isolation and identification of microflora from apparently healthy caged parrots of Dhaka Zoo of Bangladesh. Bangladesh Journal of Veterinary Medicine, v.8, n.1, p.5-10, 2010. DOI: 10.3329/bjvm.v8i 1.8349

ALLGAYER, M.C.; OLIVEIRA, S.J.; MOTTIN, V.D.; LOIKO, M.R; ABILLEIRA, F.; ROBALDO, N.M.G.; PASSOS, D.T.; WEIMER, T.A. Isolamento de Salmonella Braenderup em arara-azul (Anodorhynchus hyacinthinus). Ciência Rural, Santa Maria, v.39, n.8, p.2542-2545, 2009.

ALLEGRETTI, L. Isolamento e identificação de Lactobacillus spp., Bifidobacterium spp., Enterococcus spp., Pediococcus spp., $e$ Lactococcus spp. da microbiota intestinal de papagaio-verdadeiro (amazona aestiva). 2009. 101f. Dissertação (Mestrado em Ciências) - Faculdade de Medicina Veterinária e Zootecnia, Universidade de São Paulo, São Paulo, 2009.

BANGERT, R.L.; CHO, B.R.; WIDDERS, P.R.; STAUBER, E.H.; WARD, A.C. A survey of aerobic bacteria and fungi in the feces of healthy Psittacine birds. Avian Diseases, v.32, n. 1, p.46-52, 1988. DOI: $10.2307 / 1590947$

BARCELOS, A.S. Avaliação macroscópica, histopatológica e bacteriológica de fígados de frangos (Gallusgallus) condenados no abate pela inspeção sanitária. 2005. 83f. Dissertação (Mestrado em Medicina Veterinária Preventiva) - Universidade Federal de Santa Maria, Santa Maria, 2005. DOI: 10.2307/1590947

BARNES, H.J. Other bacterial diseases. In: SAIF, Y.M.; BARNES, H.J.; GLISSON, J.R.; FADLY, A.M.; MCDOUGALD, L.R.; SWAYNE, D. (Orgs.) Diseases of poultry. 12th.ed. Ames: lowa State Press, 2008. p.691-732.

BARNES, H.J.; NOLAN, L.K.; VAILLANCOURT, J.P. Colibacilosis. In: SAIF, Y.M.; FADLY, A.M.; GLISSON, J.R.; MCDOUGALD, L.R.; NOLAN, L.K.; SWAYNE, D.E. (Org.) Diseases of poultry. 12th.ed. Ames: lowa State Press, 2008. 1409p. Chap.18.

BARROW, P.A.; LOVELL, M.A. Experimental infection of egg-laying hens with Salmonella enteritidis phage type 4. Avian Pathology, v.20, n.2, p.335-348, 1991. DOI: 10.1080/03079459108418769
BAÚ, A.C.; CARVALHAL, J.B.; ALEIXO, J.A.G. Prevalência de salmonella em produtos de frangos e ovos de galinha comercializados em Pelotas, RS, Brasil. Ciência Rural, Santa Maria, v.31, n.2, p.303-307, 2001. DOI: http://dx.doi.org/10.1590/ So $103-84782001000200018$

BERCHIERI JÚNIOR, A. Salmonelose aviária no Brasil e no mundo. In: SIMPÓSIO DA ASSOCIAÇÃO CEARENSE DOS TÉCNICOS AVÍCOLAS - ATUALIDADES AVÍCOLAS, 5., 1999, Fortaleza, CE. Anais. Fortaleza: ACETAV, 1999. p.65-67.

BERCHIERI JR., A.; MURPY, C.K.; MARSTON, K.; BARROW, P.A. Observations on the persistence and vertical transmission of Salmonella enterica serovars Pullorum and Gallinarum in chickens: effect of bacterial and host genetic background. Avian Pathology, v.30, n.3, p.221-231, 2001 . DOI: 10.1080/03079450120054631

BEZERRA, W.G.A.; CARDOSO, W.; TEIXEIRA, R.S.C.; HORN, R.V.; MACHADO, D.N.; LOPES, E.S.; ALBUQUERQUE, A.H.; ROCHA-ESILVA, R.C. Survey of Salmonella spp. in Budgerigars (Melopsittacus undulatus) in Fortaleza, Brazil. Acta Scientiae Veterinariae, v.41, p. 1-7, 2013.

BOWMAN, T.A.; JACOBSON, E.R. Cloacal flora of clinically normal captive psittacine birds. The Journal of Zoo Animal Medicine, v. 11 , n.3, p.81-85, 1980.

BURTSCHER, C.; FALL, P.A.; WILDERER, P.A.; WUERTZ, S. Detection of Salmonella spp. and Listeria monocytogenes in suspended organic waste by nucleic acid extraction and PCR. Applied and Environmental Microbiology, v.65, n.5, p.22352237, 1999.

CORRÊA, I.M.O.; FLORES, F.; SCHNEIDERS, G.H.; PEREIRA, L.Q.; BRITO, B.G.; LOVATO, M. Detecção de fatores de virulência de Escherichia coli e análise de Salmonella spp. em psitacídeos. Pesquisa Veterinária Brasileira, v.33, n.2, p.241-246, 2013.

CROXEN, M.A.; FINLAY, B.B. Molecular mechanisms of Escherichia coli pathogenicity. Nature Reviews Microbiology, v.8, p.26-38, 2010. DOI: $10.1038 /$ nrmicro2265 
DAOUST, P.Y.; PRESCOTT, J.F. Salmonellosis. In: THOMAS, N.J.; HUNTER, D.B.; ATKINSON, C.T. (Eds.). Infectious diseases of wild birds. Ames, lowa: Blackwell, 2007. chap.13, p.270-288.

DHO-MOULIN, M.; FAIRBROTHER, J.M. Avian pathogenic Escherichia coli (APEC). Veterinary Research, v.30, p.299-316, 1999.

DORRESTEIN, G.M. Bacteriology. In: ALTMAN, R.B.; CLUBB, S.L; DORRESTEIN, G.M.; QUESENBERRY, K. Avian medicine surgery. Philadelphia: Saunders Company, 1997. p.225-280.

FALLACARA, D.M.; MONAHAN, C.M.; MORISHITA T.Y.; WACK, R.F. Fecal shedding and antimicrobial susceptibility of selected bacterial pathogens and a survey of intestinal parasites in freeliving waterfowl. Avian Diseases, v.45, n. 1, p.128-135, 2001.

FERREIRA, A.J.P.; KNÖBL, T. Colibacilose. In: BERCHIERI JR., A.; SILVA, E.; DI FÁBIO, J.; SESTI, L.; ZUANAZE, M.A.F. (Orgs.). Doença das aves. 2th.ed. Campinas: Facta, 2009. chap.4.2, p.457-500.

FLAMMER, K. Zoonosis acquired from birds. In: FOWLER, M.E.; MILLER, R.E. Zoo e wild animal medicine: current therapy. Philadelphia: W. B. Saunders, 1999. p.151-156.

FLAMMER, K.; DREWES, L.A. Species related differences in the incidence of Gram negative bacteria isolated from the cloaca of clinically normal psittacine birds. Avian Disease. v.32, n. 1 , p.79-83, 1988.

FOWLER, M.E. (Ed.). Zoo \& wild animal medicine. 3rd.ed. Philadelphia: W. B. Saunders, 1993.617p.

FRIEND, M.; FRASON, J.C. Field manual of wildlife diseases: general field procedures and diseases of birds. Madison, WI: U.S. Geological Society, 1999. 427p.

GAMA, N.M.S.Q.; BERCHIERI JR., A.; FERNANDES, S.A. Occurrence of Salmonella spp. in Laying Hens. Brazilian Journal of Poultry Science, v.5, n.1, p.15-21, 2003. DOI: 10.1590/ S1516-635X2003000100002

GAST, R.K. Salmonella infections. In: CALNEK, B.W.; BARNES, H.J. BEARD, C.W.; MCDOUGALD, L.R.; SAIF, Y.M. Diseases of poultry. 12th.ed. Ames: lowa University, 2008. chap.16, p.619-665.

GERLACH, H. Bacteria. In: RITCHIE, B.W.; HARRISON, G.J.; HARRISON, L.R. (Eds.). Avian medicine: principles and application. Lake Worth, Florida: Wingers Publishing, Inc., 1994. chap.33, p.949-983.

GIOIA-DI CHIACCHIO, R.M.; CUNHA, M.P.V.; STURN, R.M.; MORENO, A.M.; PEREIRA, C.B.P.; MARTINS, F.H.; FRANZOLIN, M.R.; PIAZZA, R.M.F.; KNÖBL, T. Shiga toxin-producing Escherichia coli (STEC): zoonotic risks associated with psittacine pet birds in home environments. Veterinary Microbiology, v. 184, p.27-30, 2016. DOI: $10.1016 /$ j.vetmic.2016.01.004

GODOY, S.N. Psittaciformes (arara, papagaio, periquito). In: CUBAS, Z.S.; SILVA, J.C.R.; CATÂO-DIAS, J.L. Tratado de animais selvagens: medicina veterinária. São Paulo: Roca, 2007. chap.16, p.222-251.

GOPEE, N.V.; ADESIYUN, A.A.; CAESAR, K. Retrospective and longitudinal study of salmonellosis in captive wildlife in Trinidad. Journal of Wildlife Diseases. v.36. n.2, p.284-293, 2000.
GRIMONT, P.A.D.; WEILL, F.X. Antigenic formulae of the Salmonella serovars. In: WORLD HEALTH ORGANIZATION (WHO). Collaborating Centre for Reference and Research on Salmonella. 9th.ed. Paris: WHO/Institut Pasteur, 2007.

HALL, A.J.; SAITO, E.K. Avian wildlife mortality events due to salmonellosis in the United States, 1985-2004. Journal of Wildlife Diseases, v.44, n.3, p.585-593, 2008. DOI: 10.7589/0090-3558-44.3.585

HIDASI, H.W.; HIDASI NETO, J.; MORAES, D.M.C.; LINHARES, G.F.C.; JAYME, V.S.; ANDRADE, M.A. Enterobacterial detection and Escherichia Coli antimicrobial resistance in parrots Seized from the illegal wildlife trade. Journal of Zoo and Wildlife Medicine, v.44, n. 1, p.1-7, 2013. DOI: 10.1638/1042-7260-44.1.

JANG, Y.H.; LEE, S.J; LIM, J.G.; LEE, H.S.; KIM, T.J.; PARK, J.H.; CHUNG, B.H.; CHOE, N.H. The rate of Salmonella spp. infection in zoo animals at Seoul Grand Park, Korea. Journal of Veterinary Science, v.9. n.2, p.177-181, 2008.

JONES, D.M.; NISBET, D.J. The gram negative bacterial flora of the avian gut. Avian Pathology, v.9, n.1, p.33-38, 1980. DOI: $10.1080 / 03079458008418383$

KANASHIRO, A.M.I.; CASTRO, A.G.M.; CARDOSO, A.L.S.P.; TESSARI, E.L.C.; JESUS C.A.M.; FERREIRA, E.; SOUZA, E.C.A. Isolamento de Salmonella Enteritidis em ovos comerciais durante rastreamento de possível fonte de infecções em humanos. Higiene Alimentar, v.16, n.101, p.76-79, 2002.

KAPER, J.B.; NATARO, J.P.; MOBLEY, H.L.T. Pathogenic Escherichia Coli. Nature Reviews, v.2, p.123-140, 2004. DOI: 10.1038/ nrmicro8 18

KEEN, J.E.; DURSO, L.M.; MEEHAN, T.P. Isolation of Salmonella enterica and shiga-toxigenic Escherichia coli 0157 from feces of animals in public contact areas of United States zoological parks. Applied and Environmental Microbiology, v.73, n. 1, p.362365, 2007.

KEUSCH, G.T.; ACHESON, D.W.K. Bactérias entéricas: diarreia secretória (aquosa). In: SCHAECHTER, M.; ENGLEBERG, N.C.; EISENSTIN, B.I.; MEDOFF, G. Microbiologia: mecanismos das doenças infeciosas. 3rd.ed. Rio de Janeiro: Guanabara Koogan, 2009. 642p. chap. 16

KNÖBL, T.; GODOY, S.N.; MATUSHIMA, E.R.; GUIMARÃES, M.B.; FERREIRA, A.J. P. Caracterização molecular dos fatores de virulência de estirpes de Escherichia coli isoladas de papagaios com colibacilose aviária. Brazilian Journal of Veterinary Research and Animal Science, v.45, p.54-60, 2008. DOI: 10.11606/ S1413-95962008000700007

KNÖBL, T.; SAIDENBERG, A.B.S.; MORENO, A.M.; GOMES, T.A.T.; VIEIRA, M.A.M.; LEITE, D.S.; BLANCO, J.E.; FERREIRA, A.J.P. Serogroups and virulence genes of Escherichia coli isolated from psittacine birds. Pesquisa Veterinária Brasileira, v.31, n. 10, p.916921, 2011 . DOI: 10.1590/SO100-736X2011001000013

KORSAK, N.; CLINQUART, A.; DAUBE, G. Salmonella sp. dans les denrées alimentaires d'origene animale: un réel probléme de santé publiqué? Annales de Médicine Véterinaire, v.148, n.4, p. 174-193, 2004 
KOTTWITZ, L.B.M.; BACK, A.; LEÃO, J.A.; ALCOCER, I.; KARAN, M.; OLIVEIRA, T.C.R.M. Contaminação por Salmonella spp. em uma cadeia de produção de ovos de uma integração de postura comercial. Arquivo Brasileiro de Medicina Veterinária e Zootecnia, v.60, n.2, p.496-498, 2008. DOI: 10.1590/ S0102-09352008000200034

KRUSE, H.; KIRKEMO, A.M.; HANDELAND, K. Wildlife as source of zoonotic infections. Emerging Infectious Diseases, v. 10, n. 12, p.2067-2072, 2004. DOI: 10.3201/eid 1012.040707

LARA, L.B. Biodisponibilidade de aminoácidos em alimentos para papagaios (Amazona aestiva) adultos. 2006. 179f. Tese (Doutorado em Ciências Agrárias) - Departamento de Zootecnia, Universidade Federal de Lavras, Lavras, 2006.

LOPES, E.S.; CARDOSO, W.M.; ALBUQUERQUE, A.H.; TEIXEIRA, R.S.C.; SALLES, R.P.R.; BEZERRA, W.G.A.; ROCHA E SILVA, R.C.; LIMA, S.V.G.; SALES, R.J.P.F.; VASCONCELOS, R.H. Isolation of Salmonella spp. in captive psittaciformes from zoos and a commercial establishment of Fortaleza, Brazil. Arquivo Brasileiro de Medicina Veterinária e Zootecnia, v.66, n.3, p.965-968, 2014. DOI: $10.1590 / 1678-41626643$

LOPES, E.S.; MACIEL, W.C.; ALBUQUERQUE, A.H.; MACHADO, D.N.; BEZERRA, W.G.A.; VASCONCELOS, R.H.; LIMA, B.P.; MARIETTOGONÇALVES, G.A.; TEIXEIRA, R.S.C. Prevalence and antimicrobial resistance profile of enterobacteria isolated from psittaciformes of illegal wildlife trade. Acta Scientiae Veterinariae, v.43, n.1313, p. 1-9, 2015.

MADEWELL, B.R.; MCCHESNEY, A.E. Salmonellosis in a human infant, a cat, and two parakeets in the same household. Journal of the American Veterinary Medical Association, v.167, n.12, p.1089-1090, 1975.

MARIETTO-GONÇALVES, G.A; ALMEIDA, S.M.; LIMA, E.T.; OKAMOTO, A.S.; PEDRO, P.; FILHO R.L.A. Isolation of Salmonella enterica Serovar Enteritidis in Blue-Fronted Amazon Parrot (Amazona aestiva). Avian Diseases, v.54, n.1, p.151-155, 2010.

MARIETTO-GONÇALVES, G.A.; ALMEIDA, S.M.; RODRIGUES, J. Presence of a human diarrheagenic Escherichia coli clone in captivity kept psittacidaes. The open microbiology Journal, v.5, n.(Suppl. 1-M4), p.72-75, 2011 . DOI: 10.2174/1874285801105010072

MARIETTO-GONÇALVES, G.A.; LIMA, E.T.; SEQUEIRA, J.L.; ANDREATTI FILHO, R.L. Colisepticemia em papagaio verdadeiro (Amazona aestiva): relato de caso. Revista Brasileira de Saúde Produção Animal, Bahia, v.8, n. 1, p.56-60, 2007.

MATTES, B.R.; CONSIGLIO, S.A.S.; ALMEIDA, B.Z.; GUIDO, M.C.; ORSI, R.B.; SILVA, R.M.; COSTA, A.; FERREIRA, A.J.P.; KNÖBL, T. Influência da biossegurança na colonização intestinal por Escherichia coli em psitacídeos. Arquivos do Instituto Biológico, v.72, n. 1, p.13-16, 2005.

MENÃO, M.C.; BOTTINO, J.A.; BIASIA, I.; FERREIRA, C.S.A.; CALDERARO, F.F.; TAVECHIO, A.L.; FERNANDES, S.; FERREIRA, A.J.P. Infecção por Salmonella Typhimurium em arara azul (Anodorhynchus hyacinthinus). Arquivos do Instituto Biológico, São Paulo, v.67, n. 1, p.43-47, 2000.
MIYAKI, C.Y.; DUARTE, M.B.; CAPARROZ, R.; NUNES, A.L.V.; WAJNTAL, A. Sex identification of South American parrots (Psittacidae, aves): using the human minisatellite probe 33.15. The Auk, v. 1 14, n.3, p.516-520, 1997.

MCPEAKE, S.J.W.; SMYTH, J.A.; BALL, H.J. Characterisation of avian pathogenic Escherichia coli (APEC) associated with colisepticaemia compared to faecal isolates from healthy birds. Veterinary Microbiology, v.1 10, n.31, p.245-253, 2005. DOI: 10.1016/j.vetmic.2005.08.001

MONTALI, R.J.; MIGAKI, G. The comparative pathology of zoo animals. Washington: Smithsonian Institution, 1980. 684p.

OLIVEIRA, C.Z.F.; BOAKARI, Y.L.; BRAGA, J.F.V.; NOBRE, M.L.M. Detecção de Salmonella sp. em papagaios (A. aestiva e A. amazona) de vida livre apreendidos no estado do Piauí. In: CONGRESSO BRASILEIRO DE MICROBIOLOGIA, 25., 2009, Porto de Galinhas, PE. Microbiologia in foco. São Paulo: 2009. v.2. p.108.

ORÓS, J.; RODRIGUEZ, J.L.; FERNANDEZ, A.; HERRAEZ, P.; MONTEROS, A.E.; JACOBSON, E.R. Simultaneous occurrence of Salmonella arizonae in a sulfur crested cockatoo (Cacatua galerita galerita) and iguanas. Avian Disease, v.42, n.4, p.818823, 1998. DOI: $10.2307 / 1592723$

OROSZ, S.E.; CHENGAPPA, M.M.; OYSTER R.A.; MORRIS, P.J.; TROCK, S.; ALTEKRUSE, S. Salmonella Enteritidis infection in two species of psittaciformes. Avian Disease, v.36, n.3, p.766$769,1992$.

PHILLIPS, W.E.; HATKIN, J.H. Isolation of Salmonella houtenae from a cockateel. Avian Diseases, v.22, n.2, p.350-353, 1978. DOI: $10.2307 / 1589549$

PICCIRILLO, A.; MAZZARIOL, S.; CALIARI, D.; MENANDRO M.L. Salmonella Typhimurium phage type DT160 infection in two moluccan cockatoos (Cacatuamoluccensis): clinical presentation and pathology. Avian Diseases, v.54, n. 1, p.131-135, 2010. DOI: http://dx.doi.org/10.1637/8969-062509-Case.1

PRIOSTE, F.E.S.; CUNHA, M.P.V.; TEIXEIRA, R.H.F.; ZWARGG, T.; GIOIA DI-CHIACCHIO, R.; MELVILLE, P.A.; BENITES, N.R.; SINHORINI, J.; MATUSHIMA, E.R.; KNÖBL, T. Genetic similarity between APEC and Escherichia coli strains isolated from Guarubaguarouba in a survey on healthy captive psittacine birds. Brazilian Journal Veterinary Research Animal Science, v.50, n.2, p. 145-51, 2013.

RAVAZZI, G.; CONZO, G. Enciclopedia mundial de los loros. Barcelona, Espanha: Editorial De Vecchi, 2008.

REAVILL, D. Bacterial diseases. In: ROSSKOPF, W.; WOERPEL, R. Disease of cage and aviary birds. 3rd.ed. Baltimore: Williams e Wilkins, 1996. 650p. p.596-612.

RIBEIRO, L.B.; SILVA, M.G. O comércio ilegal põe em risco a diversidade das aves no Brasil. Ciência e Cultura, São Paulo, v.59, n.4, p.4-5, 2007.

RITCHIE, B.W.; HARRISON, G.J.; HARRISON, L.R. (Eds.). Avian medicine: principles and application. Lake Worth, Florida: Wingers Publishing, Inc., 1994. 1384p. 
RUPLEY, A.E. Manual de clínica aviária. São Paulo: Rocca, 1999.

SAIDENBERG, A.B.; GILARDI, J.D.; MUNN, C.A.; KNÖBL, T. Evaluation of fecal gram stains and prevalence of endoparasites in freeliving macaws. Atas de Saúde Ambiental, v.3, n.3, p.3-1 1, 2015.

SAIDENBERG, A.B.; GUEDES, N.M.R.; SEIXAS, G.H.F.; ALLGAYER, M.C.; ASSIS, E.P.; SILVEIRA, L.F.; MELVILLE, P.A.; BENITES, N.R. A survey for Escherichia coli virulence factors in asymptomatic free-ranging parrots. ISRN Veterinary Science, v.2012. p.1-6, 2012a. DOI: $10.5402 / 2012 / 984813$

SAIDENBERG, A.B.; TEIXEIRA, R.H.F.; GUEDES, N.M.R.; ALLGAYER, M.C.; MELVILLE, P.A.; BENITES, N.R. Molecular detection of enteropathogenic Escherichia coli in asymptomatic captive psittacines. Pesquisa Veterinária Brasileira, v.32, n.9, p.922926, 2012 b. DOI: 10.1590/SO100-736X2012000900017

SANTIAGO, A.C.S.; LIRA-DA-SILVA, J.R.; MISE, Y.F.; LIRA-DASILVA, R.M. Tráfico de animais silvestres na Bahia. 62a. Reunião Anual da SBPC, Natal, 2010. Disponível em: <http://www.sbpcnet. org.br/livro/62ra/arquivos/jovem/ANDREZA\%20COSTA\%20 DA\%2OSILVA\%2OSANTIAGO.pdf>. Acesso em: 20 mar. 2016.

SAREYYÜPOĞLU, B.; ÇELIK, O.K.; CANTEKIN, Z.; YARDIMCI, A.H.; AKAN, M.; AKÇAY, A. Polymerase chain reaction detection of Salmonella spp. in fecal samples of pet birds. Avian Dis, v.52, n. 1, p.163-167, 2008. DOI: 10.1637/8052-070507-Reg

SCHREMMER, C.; LOHR, J.E.; WASTHULBER, U.; KÖSTERS, J.; RAVELSHOFER, K.; STEINRÜCK, H.; WIELER, L.H. Enteropatogenic Escherichia coli in Psittaciformes. Avian Pathology, v.28, n.4, p.349-354, 1999.

SEDGWICK, C.J.; ROBINSON, P.T.; LOCHNER, F.K. Zoonoses: a zoo's concern. Journal American Veterinary Medical Association, v.167, n.9, p.828-829, 1975.

SEEPERSADSINGH, N.; ADESIYUN, A.A. Prevalence and Antimicrobial Resistance of Salmonella spp. in pet mammals, reptiles, fish aquarium water, and birds in Trinidad. The Journal of Veterinary Medical Science, v.50, n. 10, p.488-493, 2003.

SIEMERING, H. Zoonosis. In: FOWLER, M. E. (Ed.). Zoo \& wild animal medicine. 2nd.ed. Philadelphia: W.B. Saunders, 1986. p.63-68.

STONE, G.G.; OBERST, R.D.; HAYS, M.P.; MCVEY, S.; CHENGAPPA, M.M. Detection of Salmonella Serovars from clinical samples by enrichment broth cultivation-PCR procedure. Journal of Clinical Microbiology, v.32, n.7, p.1742-1749, 1994.

TENAILLON, O.; SKURNIK, D.; PICARD, B.; DENAMUR, E. The population genetics of commensal Escherichia coli. Nature Reviews Microbiology, v.8, p.207-217, 2010. DOI: 10.1038/nrmicro2298

THORNLEY, C.N.; SIMMONS, G.C.; CALLAGHAN, M.L.; NICOL, C.M.; BAKER, M.G.; GILMORE, K.S.; GARRET, N.K.G. First incursion of Salmonella Typhimurium DT 160 into New Zealand. Emerging Infectious Diseases, v.9, n.4, p.493-495, 2003.

TUNCA, R.; TOPLU, N.; KURKAN, S.; AVCI, H.; AYDOGAN, A.; EPIKMEN, E.T.; TEKBIKYIK, S. Pathomorphological, immunohistochemical and bacteriological findings in budgerigars (Melopsittacusundulatus) naturally infected with S. Gallinarum. Avian Pathology, v.41, n.2, p.203-209, 2012. DOI: $10.1080 / 03079457.2012 .663076$

VANSTREELS, R.E.T.; TEIXEIRA, R.H.F.; CAMARGO, L.C.; NUNES, A.L.V.; MATUSHIMA, E.R. Impacts of animal traffic on the Brazilian Amazon parrots (Amazona species) collection of the Quinzinho de Barros Municipal Zoological Park, Brazil, 1986-2007. Zoo Biology, v.29, n.5, p.600-614, 2010. DOI: 10.1002/zoo.20300

VIGO, G.B.; ORIGLIA, J.; GORNATTI, D.; PISCOPO, M.; SALVE, A.; CAFFER, M.I.; PICHEL, M.; BINSZTEIN, N.; LEOTTA, G.A. Isolation of Salmonella Typhimurium from dead blue and gold macaws (Araararauna). Avian Diseases, v.53, n.1, p.135-138, 2009.

VILELA, V.O.; GUEDES, N.M.R.; ARAÚJO, F.R.; SOLARI, C.A.; FILIÚ, W.F.O.; CATELAN, V.L.; ALVES, M.M.; CARMO; SOUZA, R.A.; VARGAS, F.C. Salmonella Bredney em Arara-Azul (Anodorhynchus hyacinthinus). In: CONGRESSO BRASILEIRO DE ORNITOLOGIA, 9., 2001, Curitiba, PR. Ornitologia sem fronteiras. Curitiba: Fernando Costa Straube, 2001. p.390-391.

WARD, M.P.; RAMER, J.C.; FOOT, J.P.; GARNER, M.M.; SALLES, C.J.; WU, C.C. Outbreak of salmonellosis in a zoologic collection of lorikeets and lories (Trichoglossus, Lorius, and Eos sp.). Avian Diseases, v.47, n.2, p.493-498, 2003. DOI: 10.1637/0005-2086(2003)047[0493:00SIAZ]2.0.CO;2

XENOULIS, P.G.; GRAY, P.L.; BRIGHTSMIT, D.; PALCULICT, B.; SHARMAN, H.; STEINER, J.M.; TIZARD, I.; SUCHODOLSKI, J.S. Molecular characterization of the cloacal microbiota of wild and captive parrots. Veterinary Microbiology, v.146, p.320-325, 2010. DOI: 10.1016/j.vetmic.2010.05.024 